\title{
Thinking on Setting the Full-Time Professional Administrator of Research Funding
}

\author{
Huirong Cui, Zhifeng Yang \\ Academy of Opto-Electronics, Chinese Academy of Sciences, Beijing, China \\ Email: cuihuirong@sina.com, zfyang@aoe.ac.cn
}

Received 30 April 2014; revised 5 June 2014; accepted 23 June 2014

Copyright (C) 2014 by authors and Scientific Research Publishing Inc.

This work is licensed under the Creative Commons Attribution International License (CC BY). http://creativecommons.org/licenses/by/4.0/ (c) (i) Open Access

\begin{abstract}
With the development of the national economy, the investment of science and technology has been steadily increasing during the 12th five-year plan period. Based on analyzing the problems exiting in current financial management of research institutions, this paper advances the idea of setting full-time professional administrator of research funding, and probes into the importance of the administrator that should be adopted in the meticulous financial management of research funding. Then the paper makes an analysis that the administrator should have professional knowledge of the technology, management, finance and audit. Only in this way can the administrator give the guidance and supervision throughout the budget preparation, budget implementation and financial audit. It is beneficial for the research institutions in improving the meticulous management level of research funding.
\end{abstract}

\section{Keywords}

Research Funding, Full-Time Professional Administrator, Meticulous Management

\section{Introduction}

At present, the scientific research institution normally has two departments, technology research and functional management. According to the research directions, the technology research department is divided into some research centers, whose major responsibilities include studying technology solutions, settling technical problems, etc. Meanwhile the functional management department comprises finance, asset and so on, which provides strong auxiliary supports for the work of the technology research department.

The clear division is helpful for research work to some extent, but it is not conducive to improving the level of 
the research funding management for the professional limitations and poor coordination.

\section{Elaborate Present Situation of Management of Research Funding and Analyze Disadvantage of No Full-Time Professional Administrator}

Nowadays, the unscientific budgeting and non-compliance implementation are the main problems in the management of research funding. Among them, the most outstanding one is the inconsistency of the financial budget and final account.

Firstly, in the process of the project budgeting, researchers empirically compile the budget which is not examined and verified by financial staff, so the budget will be unscientific, unreasonable and imprecise. Secondly, in the process of the project implementing, the researchers use the research funding after going through strict approval procedures. In such a case, the lack of the contracts and other files often happens in the day-to-day work because the researcher has poor awareness on budget management. Then the problems do not be found in time for no-review of financial managers. Finally, it will be very difficult to successfully pass financial audits because the issues, ranging from the budgeting to implementing, induce more and more serious inconsistent problem of budgets and final accounts directly [1].

The saying goes that knowing the surface, observe the internal in order to accurately understand. For example, there is detailed analysis about the international cooperation.

As Figure 1, during the budgeting, the researcher A compiles the visiting budget of investigating autocollimator that based on the technology roadmap in German company M. During the implementing, the researcher B is responsible for the sub-systems research. For the technology improvement, the researcher B goes abroad to investigate the spectrometer that it isn't been approved in German company N. When this is over, there is nothing but the invoice. Then no problem is found, and no adjustment is made. So when the auditors arrive, in conducting audit, it is very likely that the expenditure is not approved for the inconsistent problem of budgets on autocollimator and final accounts on spectrometer.

Why? There are three reasons. Firstly, the researchers compile the budget and use the funds based on the project Leader mechanisms. The researchers are really good at technology, and not so good at actually finance and management. There is little effective communication between researchers and managers because of the different professional backgrounds, so the management is frequently separated with technology. Secondly, it has generally been known that the science research has technical and professional characteristics, which is outside the confines of managers' knowledge. Coupled with the limited time, the managers do not review all expenditures. Finally, there are very few auditors with professional technical and accounting knowledge. Most of the

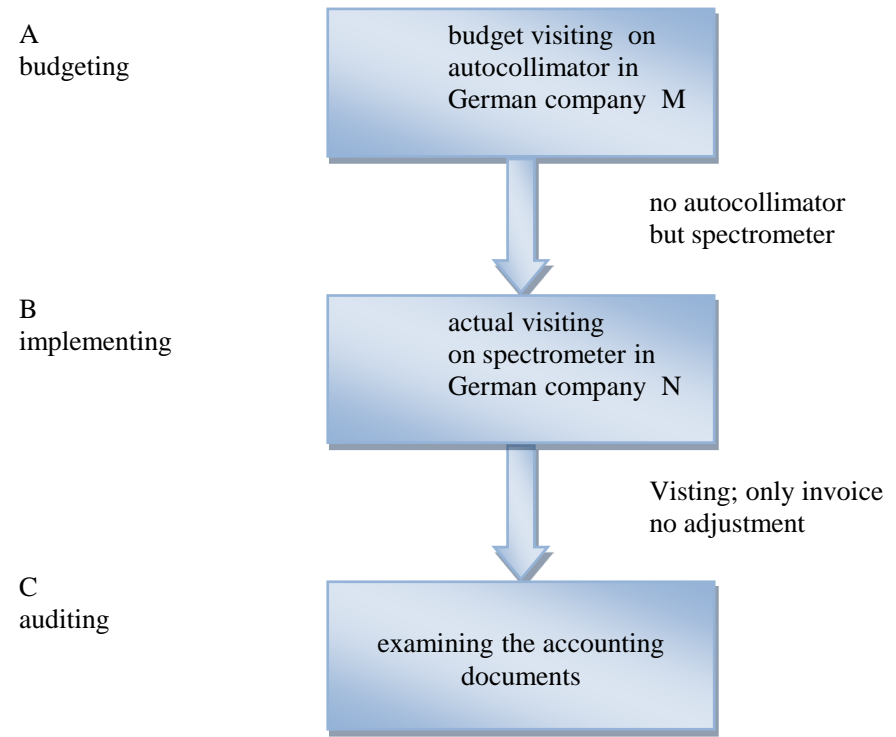

Figure 1. The inconsistency between the budget and actual expenditures on the international cooperation. 
auditors major in finance and accounting and hardly carry out better discussion on some specific questions with researchers. It can't meet the demand of the financial audit in the research funding.

In short, the researchers and managers have their merits and limits. It is vital to set a full-time professional administrator with technology, finance and management for strengthening management of research funding.

\section{Setting the Full-Time Professional Administrator with Playing a Role to Guarantee the Whole Process Management Efficiently and Effectively}

At present, the lack of comprehensive administrator in research institutions has largely affected development of management and audit of research funding. This problem not only can't be solved in a short time, but the funding management still faces more difficulty in next period of time. So it is necessary that research institutions should set the full-time comprehensive professional administrator, which can play an important role in guiding and coordinating efficiently [2].

Specifically, On the one hand, from the beginning the administrator makes a fuller use of its own technology and finance knowledge to guide researchers in preparing a scientific and reasonable budget. On the other hand, in daily work the administrator strictly controls on expense standard and range according to relevant laws and regulations. At the same time, there are a lot of uncertainties with the technology research, and the budget might be inaccurate and incomplete enough. So the administrator shall, with regard to indispensable budget adjustments, work out plans for budget adjustments. Finally, in conducting the audit, the administrator examines in advance the accounting documents, and then communicates with the auditors by simplifying the complex professional terms.

In some scientific research projects such as "National High-tech R\&D Program of China (863 Program)", "the National Basic Research Program of China (973 Program)”, and "National Key Technology Research and Development Program of the Ministry of Science and Technology of China" etc., the administrator always plays a very important role [3].

- The first point: the administrator guides the scientist to prepare budget from economic rationality and expenses standard, in order to get the evaluation experts approval budget and raise more research funds [4]. For example, the third class meeting is often held for the research institutions, so it is important in the course of establishing financial budget that the date of a meeting will be less than 2 days and the standards of relevant costs less than 450 yuan/person/day according to the national policy of the latest.

- The second point: the administrator is responsible for the whole process management of scientific research funds. It is core and meticulous that the administrator should ensure the consistency of the procurement and budget and completeness of purchasing approval procedures. And the administrator need to often reflect on what each rule means and think about how can apply ethics in budget implementation to save time and improve efficiency. At the same time the administrator is responsible for handling various reports and monthly financial report, and further analyzes the questions of the budget implementation at present and proposes solutions accordingly.

- The third point: before auditing, normally the administrator will systematically self-inspect the settlement data, finance statements and relevant vouchers and books of the research project such as Handling cash disbursements, approval of evidence-examination; handling bank settlement and standardize the use of checks. And from these, the administrator will be aware of all the details, and then communicate to the auditors more deeply for all reasonable expenditures to be fully confirmed by auditors. In conclusion, the administrator's work impact on the long-term development of the research institutions cannot be overlooked [5] [6].

As the example show, there is detailed analysis about the purchase of equipment. As Figure 2, during the budgeting, the researcher A and the administrator together compile the budget, and the administrator carefully reviews the autocollimator purchasing budget to check up the sufficiency and completeness. In the implementation process, the researcher B is responsible for the subsystem, and intends to purchase the spectrometer instead of the autocollimator for technical reasons. Next the administrator reviews the expenditure routinely, and finds the purchasing spectrometer different from the approved autocollimator, then timely prepares the budget adjustment combining with the actual situation. After receiving the adjustment approval, the administrator actively guides the researcher to perform the spectrometer procurement such as public bidding, single-source and competitive negotiation etc. When the most critical auditing is coming, the administrator has two urgent works to finish. For one thing, the administrator carefully checks the financial credentials such as contract, invoice, installation and acceptance on spectrometer in advance. For another thing, the administrator actively provides 


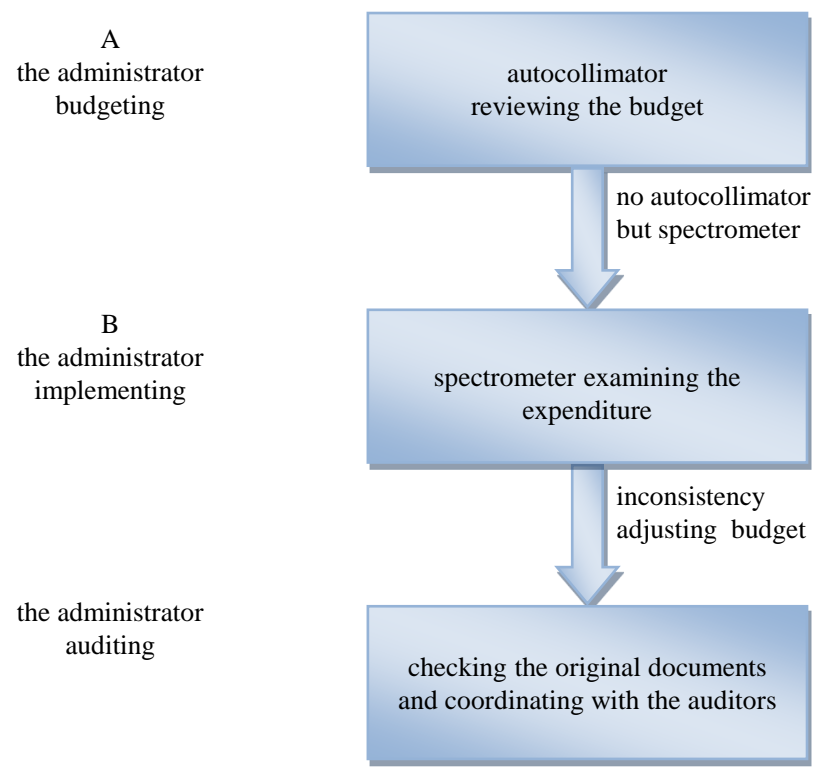

Figure 2. The consistency of the purchasing.

some documents related to the research funding for the auditors and patiently coordinates with auditors to meet the auditing requirements in auditing. Finally, the expenditure on purchasing spectrometer will be recognized by the auditors.

Above all, it is important to set the full-time professional administrator for the research institutions. The administrator who has strong knowledge of technology, management, finance and audit, can interact more effectively with people of different backgrounds. In a word, it is very significant to both the management of research funding and the long-term development of research institutions [7] [8].

\section{Strengthening the Training of the Full-Time Professional Administrator to Improve the Scientific and Meticulous Management Level for the Research Institutions}

The management of research funding, throughout the budgeting, implementing and auditing, is a comprehensive systematic engineering for the research institutions. Research institutions not only need to set the full-time professional administrator, but also shall organize them for professional studies and as far as possible provide more opportunity for them. It is one of the most necessary and effective measures to improve the scientific and meticulous management level of research funding for the research institutions [9] [10].

\section{Acknowledgements}

We are grateful to an anonymous referee for helpful comments. We also wish to thank editorial assistant of OJAcct for kind assistance and good suggestions.

\section{References}

[1] Posner, P. (2004) Program Assessment Rating Tool Presents Opportunities and Challenges for Budget and Performance Integration. GAO, USA.

[2] Madole, J., Cook, J. and Guice, I. (2006) Post-Award Administration: A Brief Overview of OMB Circulars [R/OL]. Proceedings of NCURA Spring Region V Meeting, Austin, 7-10 May 2006, 424-426.

[3] Cui, H.R., et al. (2013) Reflection on Strengthening the Audit Supervision of the Large Assets in Research Funding. Technology and Innovation Management, 34, 424-426.

[4] Liu, J.J. (2011) Present Situation and Strategy of Scientific Research Funds in Local Comprehensive Universities. Technology and Innovation Management, 32, 328-331.

[5] Fisher, J.G., Peffer, S.A. and Sprinkle, G.B. (2003) Budget Based Contracts, Budget Levels, and Group Performance. 
Journal of Management Accounting Research, 5, 1-74.

[6] Ouyang, Z.S., et al. (2013) Enlightenment of the Reform of Government Accounting in Canada and USA. Accounting Research, 11, 3-7.

[7] Frow, N., Marginson, D. and Ogden, S. (2010) “Continuous” Budgeting: Reconciling Budget Flexibility with Budgetary Control. Accounting, Organizations and Society, 35, 444-461. http://dx.doi.org/10.1016/j.aos.2009.10.003

[8] Libby, T. and Lindsay, R.M. (2010) Beyond Budgeting or Budgeting Reconsidered? A Survey of North-American Budgeting Practice. Management Accounting Research, 21, 56-75. http://dx.doi.org/10.1016/j.mar.2009.10.003

[9] Covaleski, M.A., et al. (2003) Budgeting Research: Three Theoretical Perspectives and Criteria for Selective Integration. Journal of Management Accounting Research, 15, 3-49. http://dx.doi.org/10.2308/jmar.2003.15.1.3

[10] Dai, G.Q. (2006) The Research Funds Supervision and Inspiration from American Federal Government. Scientific Research Management, 27, 17-22. 
Scientific Research Publishing (SCIRP) is one of the largest Open Access journal publishers. It is currently publishing more than 200 open access, online, peer-reviewed journals covering a wide range of academic disciplines. SCIRP serves the worldwide academic communities and contributes to the progress and application of science with its publication.

Other selected journals from SCIRP are listed as below. Submit your manuscript to us via either submit@scirp.org or Online Submission Portal.
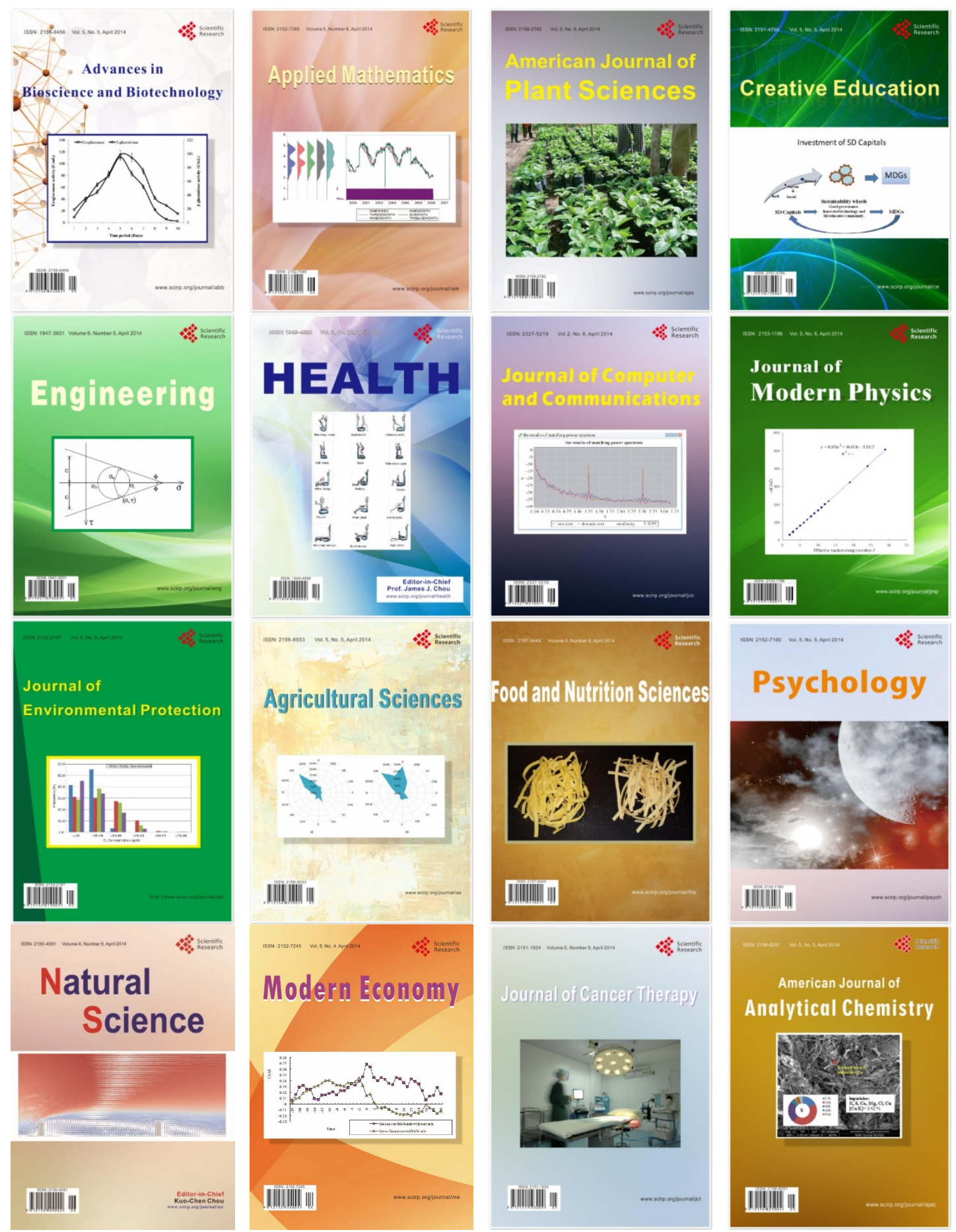